\title{
Ultrasonic Guided Wave Propagation through Welded Lap Joints
}

\author{
Audrius Jankauskas * and Liudas Mazeika
}

Prof. K. Barsauskas Ultrasound Research Institute, Kaunas University of Technology, K. Barsausko str. 59, Kaunas LT-51423, Lithuania; liudas.mazeika@ktu.lt

* Correspondence: audrius.jankauskas@ktu.lt; Tel.: +370-37-351-162

Academic Editors: João Manuel R. S. Tavares and Victor Hugo C. de Albuquerque Received: 30 September 2016; Accepted: 6 December 2016; Published: 10 December 2016

\begin{abstract}
The objective of the research presented here is the investigation of ultrasonic guided wave (UGW) propagation through the lap joint welded plates used in the construction of a storage tank floors. The investigations have been performed using numerical simulation by finite element method (FEM) and tested by measurement of the transmission losses of the guided waves transmitted through the welded lap joints. Propagation of the symmetric $S_{0}$ mode in the welded stainless steel plates in the cases of different lap joint overlap width, operation frequency, and additional plate bonding caused by corrosion were investigated. It was shown that the transmission losses of the $S_{0}$ mode can vary in the range of $2 \mathrm{~dB}$ to $8 \mathrm{~dB}$ depending on the ratio between lap joint width and wavelength. It was also demonstrated that additional bonding in the overlap zone caused by corrosion can essentially reduce transmission losses.
\end{abstract}

Keywords: ultrasonic non-destructive testing; guided waves; lap welds; storage tanks

\section{Introduction}

In the petrochemical industry, corroded areas of a storage tank floor are an object of non-destructive testing (NDT). For this reason, testing for a high level of safety and the reliability of periodical maintenance of the tank and its floor should be performed, in order to avoid corrosion related accidents when hazardous chemical materials might get into the environment and groundwater. In order to avoid this, various NDT methods for the inspection of the construction elements in the petrochemical industry, such as penetrant testing, magnetics [1], eddy current [2], thermography [3,4], radiographic testing [5], acoustic emission [6], and ultrasonic techniques are used [7,8]. The main problems related to the inspection of the storage tanks and their floors using conventional NDT methods is that, in most cases, the tank has to be emptied, cleaned, and made safe for human entry before any inspection could be performed. It causes large financial and time costs to perform these operations.

In this regard, the most promising technique which enables inspection at relatively long distances (up to $100 \mathrm{~m}$ ) and can be used for the inspection of storage tank floor from an outside perimeter of the tank is ultrasonic inspection method, based on the application of ultrasonic guided waves (UGW). Advantages of such a technique were successfully demonstrated on the long range applications for rapid screening of pipes [9-12], rails [13,14] and transmission lines [15]. At present, UGW technology is used primarily to detect and locate defective areas. A significant number of studies on the interaction of UGW with discontinuities in flat plates [16-19] and pipes [20-24] have been reported by a number of researchers. One challenge in UGW inspection is that general corrosion occurring over a large surface area may not create reflection sufficient for detections. In this regard, the primary effect on guided wave inspection when corrosion is present is an increase in the attenuation of UGW energy. If the attenuation is measured, it may be possible to produce an estimate of the degree of corrosion through the inspected 
object [23]. Unfortunately, other mechanisms besides corrosion such as additional coatings [23,25], loadings [26], temperature [23], construction features—e.g., welds, bends, and branches—can produce an increase of guided wave attenuation and influence the achievable inspection range. In the case of the tank floor, the attenuation of UGW is mainly conditioned by the leakage of guided waves to the liquid and the losses in the welded lap joints. It is necessary to take into account that, in order to propagate the whole tank floor, the UGW needs to pass multiple welds. Therefore, estimation of losses on the lap joint welds is a critical issue in determination of possibilities of such an approach.

A huge amount of work has been produced on the general topic of UGW propagation in lap joint connected objects, mainly targeting adhesively bonded [27-32], bolted [33], and brazed [34] lap joints. However, little attention was paid to metal plates joined using lap welds. It is necessary to underline that lap joint welds are essentially different from listed ones as it has narrow weld part and relatively wide unwelded part (overlap zone). Additionally, the contact condition in the overlap zone can vary due the heavy load of the filled tank, humidity, or partial corrosion. The influence of these parameters on the attenuation of the guided waves propagating through the weld have not been investigated sufficiently. So, the purpose of the research presented is to determine regularities and assess transmission losses of the UGW propagating through lap welds and to investigate how they are affected by the different lap weld overlap widths, operation frequency, and variation of bonding condition in overlap zone.

\section{Numerical Simulation of the Guided Waves Propagation}

\subsection{Dispersion Curves}

In the case of long range UGW application, the objects being tested are big and consequently the test samples for the inspection technique development also are big and expensive to manufacture, as well impractical to use in laboratory conditions. Due to this reason, we decided to use scaled-down physical and numerical models of the object simultaneously. In a corresponding way, we changed the operation frequency. Such an approach is valid as the properties of UGW depend on frequency-thickness product $f d$ and linear acoustic propagation is assumed. This means that, if the dimensions of the object-including plate thickness-are reduced by the factor $N$ then the frequency of selected ultrasonic waves will be higher by the same factor $N$ and the properties of the guide wave will be the same. So, instead of investigating large objects, it is reasonable to carry out investigations with the scaled-down models and verify determined regularities on a real-sized object afterwards.

In order to answer the questions related to UGW propagation in a tank floor constructed out of multiple lap joint welded plates, models with the scaling factor 1:8 were developed and investigated. Investigations were carried out by using stainless steel plates. The elastic properties of materials used in the numerical model were as follows: density $\rho=8000 \mathrm{~kg} / \mathrm{m}^{3}$, Young's modulus $E=193 \mathrm{GPa}$, shear modulus $G=77.2 \mathrm{GPa}$, and Poisson's ratio $v=0.31$. In order to properly select the operation frequency and modes suitable for investigation, the dispersion curves of the phase $c_{\mathrm{ph}}$ and group $c_{\mathrm{gr}}$ velocities in the $8 \mathrm{~mm}$ thickness and in the scaled-down $1 \mathrm{~mm}$ thickness stainless steel plates were calculated using the semi-analytical finite element (SAFE) method [35,36]. The algorithm of the method was implemented by the authors. The calculated dispersion curves of UGW are presented in Figure 1. The dashed line denotes the frequency selected for investigations. This frequency for a real-sized object is $50 \mathrm{kHz}$, and for a scaled-down model is $400 \mathrm{kHz}$. The product $f d$ in both cases is the same. The velocities of the fundamental guided wave modes in the case of $1 \mathrm{~mm}$ thickness steel plate at the selected operation frequency are presented in Table 1. 


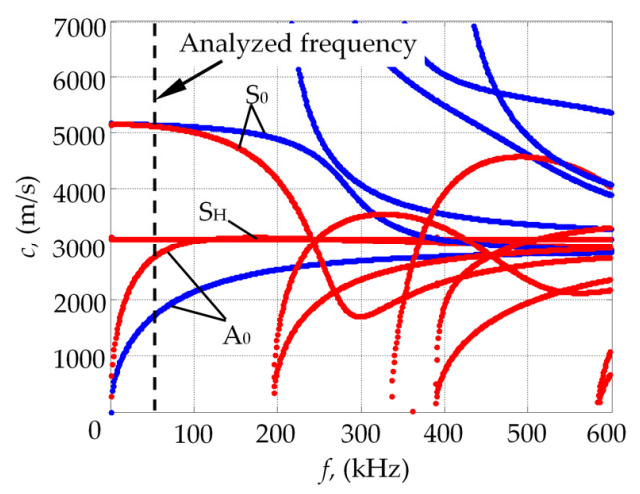

(a)

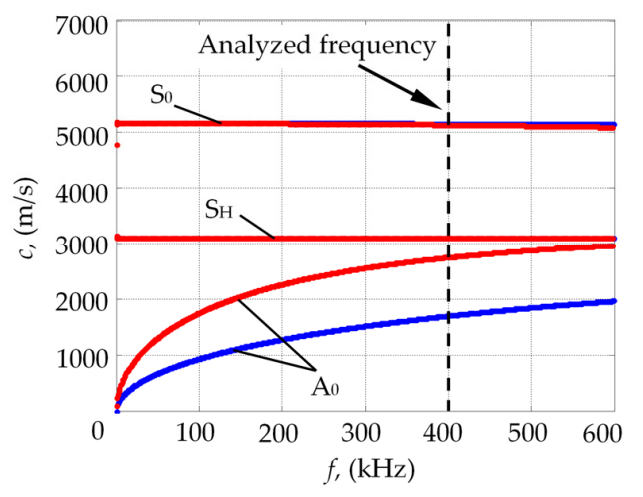

(b)

Figure 1. Ultrasonic guided waves phase (blue) and group (red) velocities dispersion curves for: (a) $8 \mathrm{~mm}$ thickness stainless steel plate; (b) $1 \mathrm{~mm}$ thickness stainless steel plate.

Table 1. Velocity of the asymmetric $A_{0}$, symmetric $S_{0}$, and shear horizontal $S_{H}$ guided waves modes at $400 \mathrm{kHz}$ frequency for $1 \mathrm{~mm}$ thickness stainless steel plate.

\begin{tabular}{ccc}
\hline Guided Wave Mode & Phase Velocity $c_{\boldsymbol{p h}}, \mathbf{m} / \mathbf{s}$ & Group Velocity $c_{\boldsymbol{g r}}, \mathbf{m} / \mathbf{s}$ \\
\hline Asymmetric $\mathrm{A}_{0}$ & 1701 & 2751 \\
Symmetric $\mathrm{S}_{0}$ & 5156 & 5134 \\
Shear horizontal $\mathrm{S}_{\mathrm{H}}$ & 3106 & 3106 \\
\hline
\end{tabular}

The symmetric $S_{0}$ guided wave mode was selected for analysis due to several key properties of this wave mode [37]:

- the group velocity of the symmetric $S_{0}$ wave mode is highest, ensuring that it arrives before any other modes, thus making it easier to identify and separate the time interval in the measured signals;

- $\quad$ symmetric $S_{0}$ wave mode is less sensitive to liquid boundary interaction. It has lower attenuation and leakage losses compared to the asymmetric $\mathrm{A}_{0}$ wave mode, thus it enables stronger signals to be received at a longer propagation distance.

\subsection{Transmission Losses Dependence from Lap Joint Width and Operation Frequency}

In order to investigate how the welded lap joint overlap zone width $\Delta l$ influences propagation of the UGW symmetric $S_{0}$ mode and its transmission losses $\alpha_{\mathrm{S} 0}(f)$ the numerical modelling was carried out using the finite element (FE) method. The model of the lap joint used in the numerical investigation is presented in Figure 2. It should be noted that the model is presented on different vertical and horizontal scales.

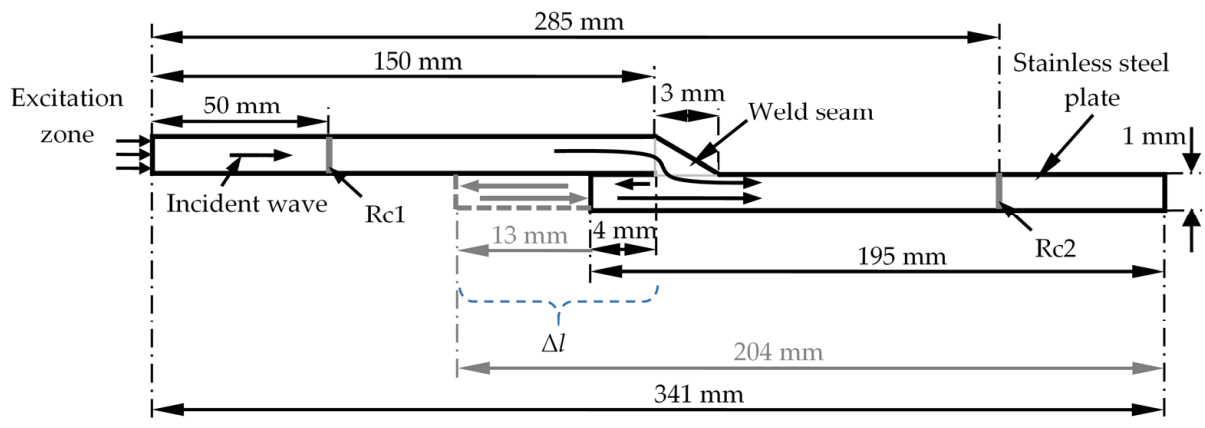

Figure 2. Model used for the investigation of the symmetric $\mathrm{S}_{0}$ guided wave mode transmission through the different width $\Delta l$ lap joint welded plates. 
The ANSYS finite element software was used to obtain wave propagation through the 2D geometry which includes an implicit algorithm with Newmark time integration method for solving the transient wave propagation. The model of elastic wave propagation is based on the assumption of linear elasticity and solution of the Navier equation of the elastic wave motion in matrix form [38-44]:

$$
\mathbf{M} \ddot{\mathbf{u}}+\mathbf{C} \dot{\mathbf{u}}+\mathbf{K u}=\mathbf{F}
$$

where $\mathbf{M}$ is the mass matrix, $\mathbf{C}$ is the damping matrix, $\mathbf{K}$ is the stiffness matrix, $\mathbf{u}, \dot{\mathbf{u}}, \ddot{\mathbf{u}}-$ are the nodal displacement, velocity, and acceleration vectors, respectively, $\mathbf{F}$ is the externally applied excitation nodal forces. To simplify the model, a linear elastic solid is considered and no damping is added in this study $(\mathbf{C}=0)$. The model under investigation was considered to be infinite in the $z$ direction so that the plane strain condition is used, which assumes that all strains occurs in the $x-y$ direction and there are no strains in the $z$ direction. Four-node PLANE42 linear elements were used to represent the 2D section in the plane strain. The element has four nodes, each with two degrees of freedom-translations in the nodal $x$ and $y$ directions. The spatial size of the finite element was set to $0.2 \mathrm{~mm}$, which corresponds to 21 elements per wavelength in accordance with the minimum wavelength of the slowest asymmetric $A_{0}$ wave mode at the $400 \mathrm{kHz}$ frequency (Table 1). The excitation was performed by applying longitudinal force as five periods of $400 \mathrm{kHz}$ sine-burst with the Gaussian envelope signal to the edge of the model (Figure 2). The time integration step $\mathrm{d} t=10 \mathrm{~ns}$ is equal to $1 / 250$ of the period at $400 \mathrm{kHz}$ central frequency. The time interval used for the modelling of elastic wave propagation was $\Delta t=0 \div 80 \mu \mathrm{s}$. The overlap zone width $\Delta l$ of the lap joint between welded plates was gradually changed from $4 \mathrm{~mm}$ up to $13 \mathrm{~mm}$ by steps of $1 \mathrm{~mm}$. The material elastic properties in the modelling were used such as presented in Section 2.1.

The signals corresponding to the fastest propagating symmetric $\mathrm{S}_{0} \mathrm{UGW}$ mode were acquired by selecting the sets of nodes at the positions Rc1, $50 \mathrm{~mm}$ and Rc2, $285 \mathrm{~mm}$ distance from the excitation zone. The position Rc1 is situated before the lap joint weld and Rc2-after the lap joint weld, respectively. The distances were selected in a way that ensured the sufficient time domain separation of different guided wave mode signals. The received signal was assumed to be the mean value of the longitudinal particle velocity across the plate thickness, which was calculated by using the following presented expression:

$$
u(t)=\frac{1}{N_{e}} \sum_{n=1}^{N_{e}} u_{n}(t)
$$

where, $N_{e}$ is the number of nodes and $u_{n}$ is the nodal value of the longitudinal particle velocity in node $n$. The time intervals corresponding to the fastest propagating symmetric $\mathrm{S}_{0}$ UGW mode signals were selected from the time diagrams of the received signals by using the Hanning window. The transmission losses $\alpha_{S_{0}}(f)$ of the selected wave mode were calculated by using the following equation:

$$
\alpha_{\mathrm{S} 0}(f)=-20 \lg \frac{\left|\mathrm{FT}\left[u_{1}(t)\right]\right|}{\left|\mathrm{FT}\left[u_{\mathrm{r}}(t)\right]\right|}
$$

where, $u_{\mathrm{r}}(t)$ is the reference ultrasonic signal (picked-up by the virtual receiver Rc1 before the weld), $u_{1}(t)$ is the ultrasonic signal transmitted through the weld (picked-up by the virtual receiver Rc 2 behind the weld), FT denotes Fourier transform. The obtained waveforms of the signals in the time domain of the ultrasonic symmetric $S_{0}$ wave mode are presented in Figure 3. The variations of the signal amplitude related to different widths of the overlap zone can be observed (Figure $3 b$ ). The obtained transmission losses $\alpha_{S 0}(f)$ of the symmetric $S_{0}$ wave mode for the current lap joint weld width $\Delta l$ meaning were acquired by taking the value corresponding to the frequency $f=400 \mathrm{kHz}$. The obtained transmission losses dependence versus plate overlap zone width is presented in Figure 4, where dots denote transmission losses value obtained by FE analysis, and the solid line denotes the interpolation by piecewise cubic Hermite polynomial. 


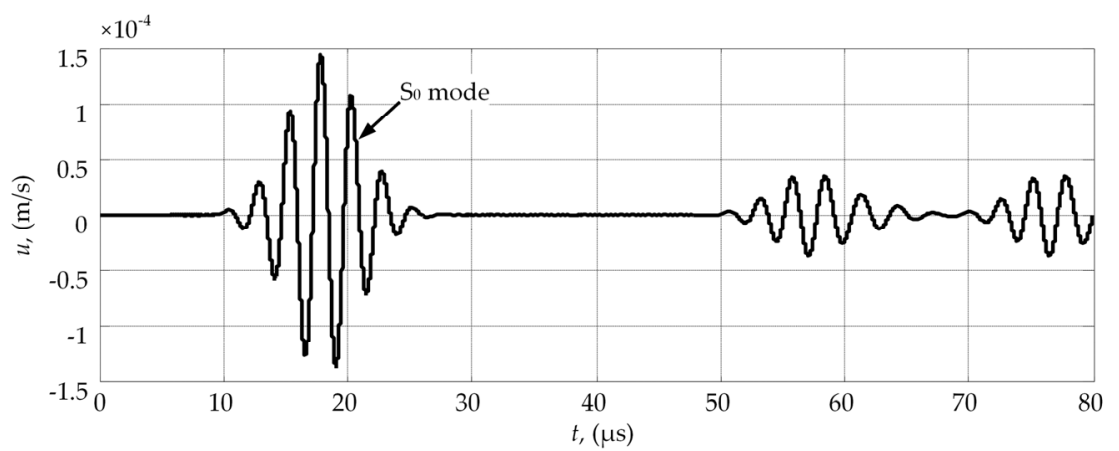

(a)

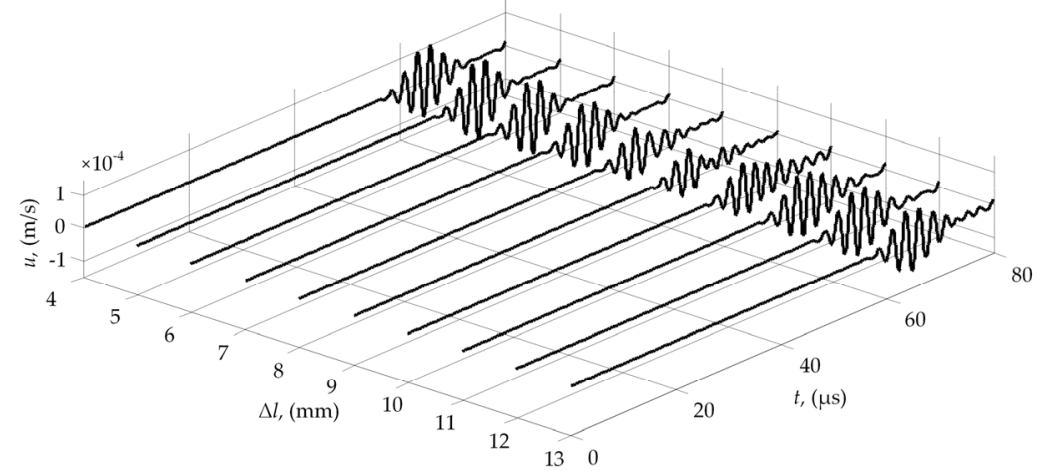

(b)

Figure 3. The waveforms of the signals measured: (a) before lap joint connection at Rc1 position; (b) after lap joint connection at Rc2 position in the case of different overlap zone width $\Delta l$.

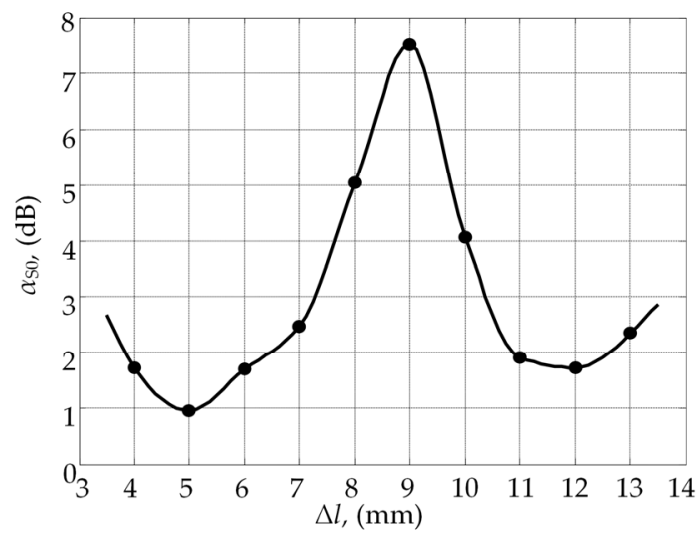

Figure 4. The transmission losses $\alpha_{S_{0}}(f)$ of the $S_{0}$ guided wave mode in the case of different lap joint overlap zone width $\Delta l$.

It was observed that the overlap zone width $\Delta l$ in the welded lap joint essentially influences the transmission losses $\alpha_{S 0}(f)$ of the analyzed symmetric $S_{0}$ wave mode and varies from $1 \mathrm{~dB} /$ weld up to $7.5 \mathrm{~dB} /$ weld depending on lap joint overlap width. The results demonstrated that the highest transmission losses $\alpha_{S_{0}}(f)$ of the symmetric $S_{0}$ wave mode are obtained in the case of $9 \mathrm{~mm}$ overlap zone width. The obtained dependence of transmission losses $\alpha_{S 0}(f)$ can be explained by the fact that UGW are reflecting back and forth within the free edge of the overlapped part of the plate and this produces a series of signals which interfere with each other in such a way that it becomes essentially dependent on the length of propagation path which is defined by the width of the overlapped zone. On the other hand, it means that it is dependent on the wavelength $\lambda$ of the symmetric $S_{0}$ wave mode. 
In order to determine how the transmission losses $\alpha_{S 0}(f)$ of the symmetric $S_{0}$ wave mode for particular lap joint overlap zone widths depend on excitation frequency, numerical modelling was carried out. The frequency of the excitation signal (five periods of sine-burst with a Gaussian envelope) was changed in the frequency range from $150 \mathrm{kHz}$ up to $500 \mathrm{kHz}$ with $25 \mathrm{kHz}$ steps. Obtained dependencies of the transmission losses $\alpha_{S 0}(f)$ in the case of different frequencies and different overlap zone widths $(\Delta l=4 \mathrm{~mm}, \Delta l=9 \mathrm{~mm}, \Delta l=13 \mathrm{~mm})$ are presented in Figure 5 .

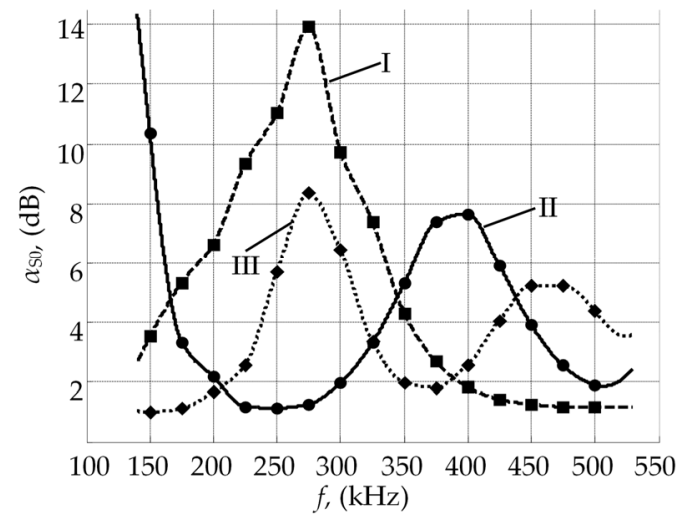

Figure 5. The transmission losses $\alpha_{\mathrm{S} 0}(f)$ of the $\mathrm{S}_{0}$ guided wave mode for the different excitation signal frequency in the case of I: $4 \mathrm{~mm}$ overlap, II: $9 \mathrm{~mm}$ overlap, and III: $13 \mathrm{~mm}$ lap joint overlap widths (dots: FE analysis results, solid line: interpolation by piecewise cubic Hermite polynomial).

The presented results demonstrate that there are some regular changes of maxima and minima in the dependency of the transmission losses versus frequency. The dependency of the transmission losses versus frequency is different for different overlap zone widths. In this case, it can be assumed that the superposition of the direct waves and the waves reflected by the free end of lap joint of $S_{0}$ wave mode signals takes place, and hence depending on the total width of the lap joint $\Delta l$, leads to a larger or lover amplitude of the resultant wave. In the case of the single-edge closed reflector, the maxima or minima will appear at every integer number of $\frac{1}{4} \lambda$ per lap joint width (Figure 6a). So, it can be stated that the increase of transmission losses $\alpha_{S 0}(f)$ of symmetric $S_{0}$ wave mode transmitted through the lap joint is expected at every odd number of $\frac{1}{4} \lambda$ per lap joint width. Meanwhile, on the even number of $\frac{1}{4} \lambda$ per lap joint width, a reduction of the transmission losses could be observed. This regularity can be expressed by

$$
\begin{aligned}
& \alpha_{S 0}(f, \Delta l)=\max \left(\frac{n \cdot c_{\mathrm{gr}}}{4 f}\right), n=1,3,5, \ldots \\
& \alpha_{S 0}(f, \Delta l)=\min \left(\frac{n \cdot c_{\mathrm{gr}}}{4 f}\right), n=2,4,6, \ldots
\end{aligned}
$$

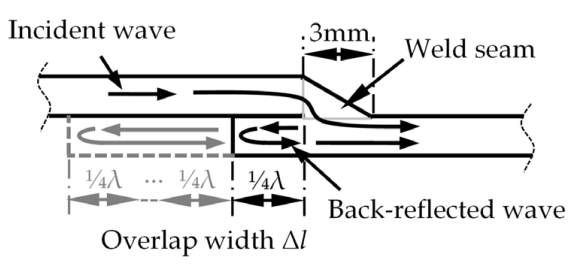

(a)

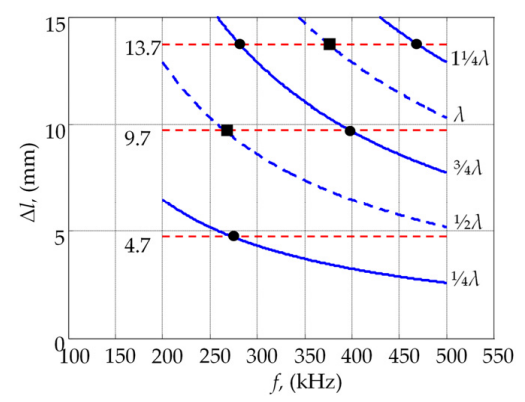

(b)

Figure 6. (a) Wave propagation and reflection in the lap joint connection; (b) dependence of the transmission losses local maxima and minima from the wavelength for particular lap joint width (square: local minima, dots: local maxima od the transmission losses). 
The graphical representation of the maxima and minima of transmission losses $\alpha_{S 0}(f)$ versus frequency and lap joint width $\Delta l$ are presented in Figure $6 \mathrm{~b}$.

The numerical investigation performed on the UGW propagation through the single lap joint welded connection demonstrated that the overall transmission losses $\alpha_{S_{0}}(f)$ of the symmetric $\mathrm{S}_{0}$ wave mode are strongly dependent on the selected system parameters, such as width of lap joint $\Delta l$ and operation frequency. Thus, it was observed that-depending on the wavelength per lap joint width-the increase (related to the odd number of $\frac{1}{4} \lambda$ ) or reduction (related to the even number of $\frac{1}{4} \lambda$ ) of transmission losses could be observed.

\subsection{Transmission Losses Dependence on Plates Bonding}

As was demonstrated in investigations carried out earlier by a number of researchers, the dispersive behavior of UGW is strongly dependent on the bonding state between lap joint connected objects $[27,29-32,45,46]$. Thus, the velocity and amplitude of UGW signals transmitted through lap joint are among the main parameters to be affected [27-29]. Typically, in adhesive bonding, the elastic waves are transmitted through the adhesive layer in the overlap region where the adhesive serves as a medium for wave transmission and the overall efficiency of the transmission is mostly affected by the width of the lap joint area and adhesive layer parameters by itself. In contrast to adhesively bonded lap joints, lap joints produced in storage tank floor construction are commonly connected only by the weld seam. The overlap zone which in its original state does not possess acoustic coupling between the upper and lower plates during long period of tank exploitation (usually design life of an aboveground storage tank is 25 years, but in some cases may be in use for 50-70 years) leads to partial cohesion of the plates in overlap zone. The physical factors leading to it can be pressure of the filled tank, moisture retention in the lap and corrosion. How such phenomena are affecting transmission losses $\alpha_{S 0}(f)$ of the selected $S_{0}$ guided wave mode was the task for the second stage of investigation.

To achieve this goal, three cases of the UGW propagation through the lap joint welded plates were analyzed (Figure 7):

(a) plates are connected only at the weld seam position (Figure 7b);

(b) partially bonded plates (50\% cohesion) (Figure 7c);

(c) fully bonded plates ( $100 \%$ cohesion) (Figure $7 \mathrm{~d})$.

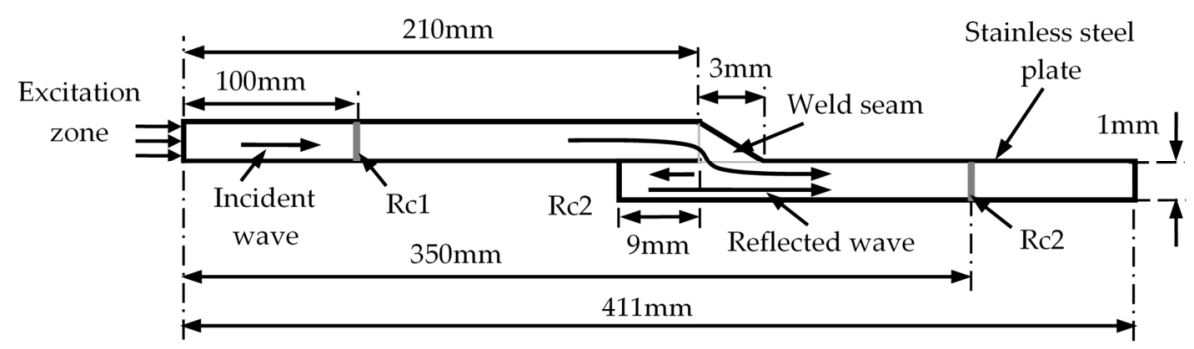

(a)

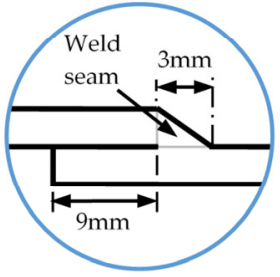

(b)

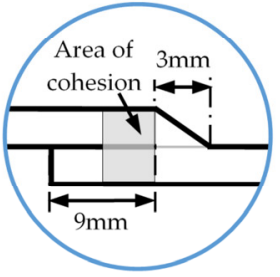

(c)

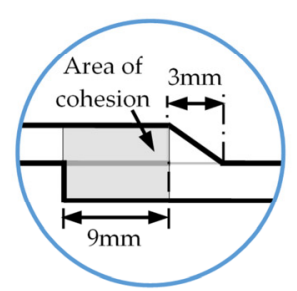

(d)

Figure 7. (a) Model used for the investigation of the symmetric $S_{0}$ wave mode propagation through the lap joint in the case of: (b) plates are connected only at the weld seam position; (c) partially bonded plates; (d) fully bonded plates. 
The modelling was performed by using the same FE model parameters as those presented in the previous subsection. During the modelling, it was assumed that-due to cohesion of the plates in overlap region-there is solid contact. In the case of solid contact, it was assumed that the contact layer between plates has the properties of stainless steel. This means that the contact allows the propagation of both normal and tangential components of the waves. The transmission losses $\alpha_{\mathrm{S} 0}(f)$ of the selected wave mode were calculated by comparing the spectra of the acquired $S_{0}$ wave mode signals, observed before lap joint connection and after it, by using Equation (3) presented earlier. The predicted transmission losses $\alpha_{S 0}(f)$ of the analyzed symmetric $S_{0}$ wave mode for different plate bonding conditions are presented in Figure 8.

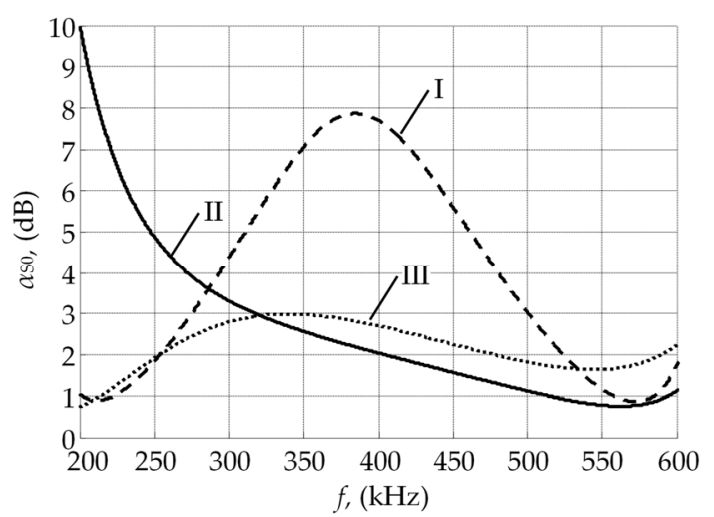

Figure 8. The transmission losses $\alpha_{S 0}(f)$ of the $S_{0}$ wave mode at different lap joint bonding conditions in the case: I: plates are connected only at the weld seam position, II: partially bonded plates, III: fully bonded plates.

The numerical investigation that we carried out demonstrated that the highest transmission losses $\alpha_{\mathrm{S} 0}(f)$ of the analyzed ultrasonic symmetric $S_{0}$ guided wave mode are obtained in the case where plates in the lap joint are connected only by the weld seam. The predicted value of the transmission losses $\alpha_{\mathrm{S} 0}(f)$ of $\mathrm{S}_{0}$ mode at $400 \mathrm{kHz}$ frequency were estimated to be $7.7 \mathrm{~dB} /$ weld. Meanwhile, in the case of the partially and fully bonded lap joints, these transmission losses of the $S_{0}$ wave mode were obtained to be $2.1 \mathrm{~dB} /$ weld and $2.7 \mathrm{~dB} /$ weld, respectively. Such a decrease of the transmission losses $\alpha_{\mathrm{S} 0}(f)$ for the analyzed symmetric $S_{0}$ guided wave mode in the case of the partially and fully bonded lap joint welds may be explained by the fact that due cohesion changes the width of the connection zone between lap joint welded plates. The performed numerical modelling demonstrated that average value of the transmission losses of symmetric $S_{0}$ wave mode were at a level of $8 \mathrm{~dB} /$ weld, but additionally these losses strongly depend on cohesion between plates. Taking into account that there can be $10 \mathrm{~s}$ of welds across the tank floor, the total transmission losses may exceed $100 \mathrm{~dB}$. However, considering possible plate cohesion in the overlap region, those losses are expected to be much lower.

\section{Experimental Investigation of Guided Wave Propagation through Lap Joints}

The objective of this part was the experimental verification of the modelling results, obtained using a finite element model. For this purpose, the special test sample was manufactured by welding two $1 \mathrm{~mm}$-thick stainless steel plates together. The plates were welded using lap welds with different overlap zone width $\Delta l$, which linearly change from $2 \mathrm{~mm}$ up to $15 \mathrm{~mm}$ (Figure 9). The width of the weld seam was $3 \mathrm{~mm}$. Experimental investigation of the ultrasonic symmetric $S_{0}$ guided wave mode propagation through the welded lap joint was performed using the experimental set-up presented in Figure 9. 


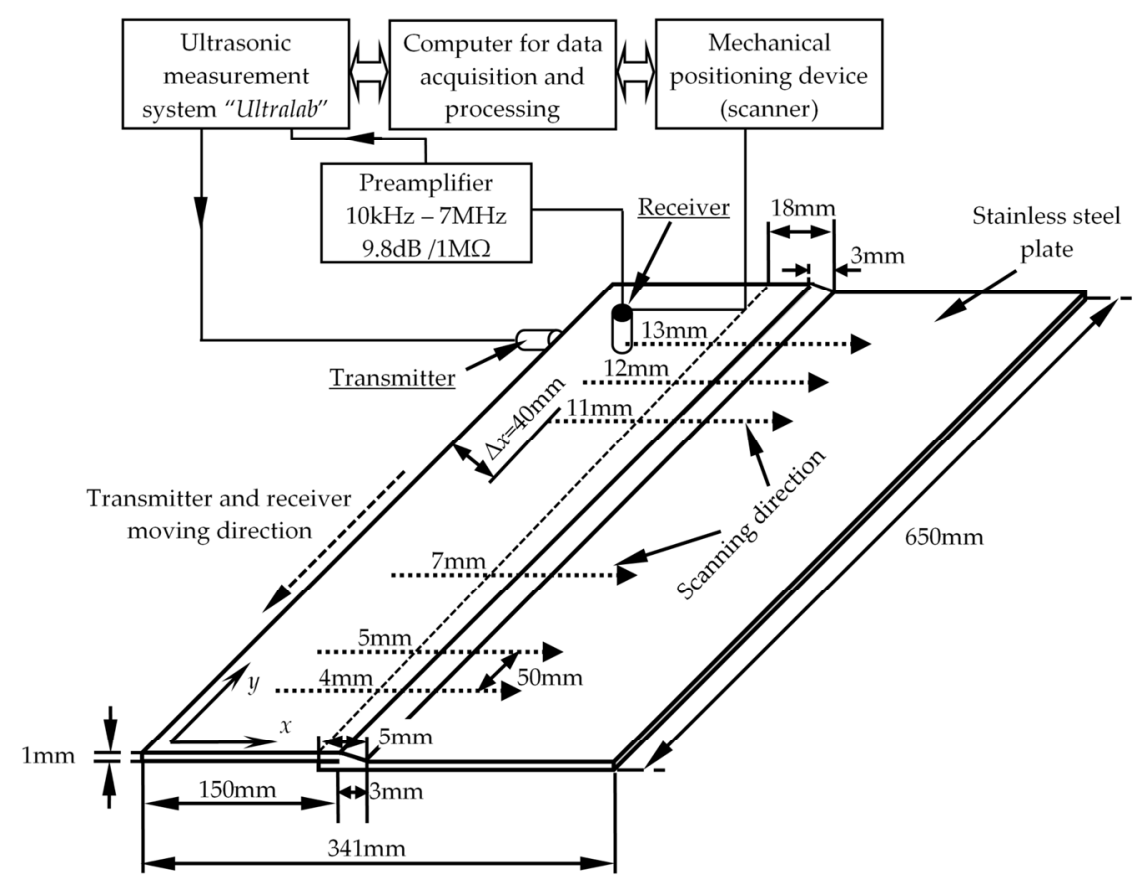

Figure 9. Experimental set-up for the investigation of the ultrasonic $S_{0}$ guided wave mode propagation through the lap joint welded plates with different overlap zone width $\Delta l$.

The low frequency ultrasonic measurement system "Ultralab", produced and manufactured at Prof. K. Barsauskas Ultrasound Research Institute of Kaunas University of Technology, was used as the control instrument for measurements. The wideband ultrasonic transducers operating in the thickness mode were used for the generation and reception of the ultrasonic guided wave signals. The excitation was performed by using three periods of rectangular pulse with a frequency of $400 \mathrm{kHz}$ and an amplitude of $300 \mathrm{~V}$. The reception of the propagating ultrasonic guided waves was performed by using low frequency ultrasonic transducer having special wear-proof convex form replaceable protector made out of fiberglass with a contact area of $1 \mathrm{~mm}$ [47-49]. The frequency responses of the ultrasonic transducers used as the transmitter and the transducer used as the receiver are shown in Figure 10. The sampling frequency $f_{\mathrm{s}}$ was selected $f_{\mathrm{s}}=100 \mathrm{MHz}$, the frequency range of the amplifier filters was $0.02 \mathrm{MHz}-2 \mathrm{MHz}$ and the total gain of amplifiers was $45 \mathrm{~dB}$.

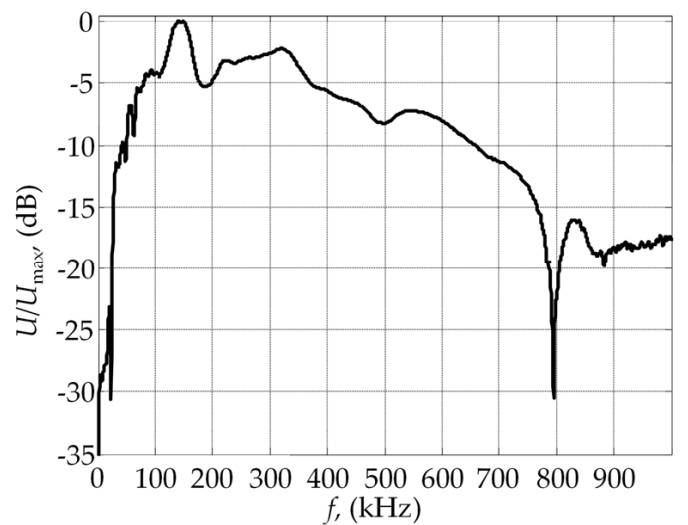

(a)

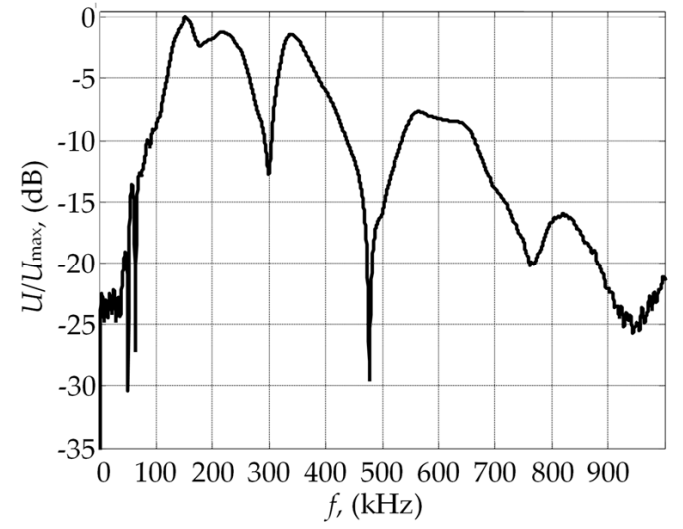

(b)

Figure 10. The frequency responses of the (a) transmitter and (b) receiver with convex protector (the equivalent diameter of the contact area $1 \mathrm{~mm}$ ). 
The experiments were carried out in the following way. The transmitter was attached at the first position to the edge of the stainless steel plate (in order to create the longitudinal force) using specially developed spring-type adjusters and the receiver was scanned across the weld in the $x$ direction (Figure 8). Scanning of the test sample for the B-scan type data collection of the propagating ultrasonic guided waves was performed by using a one-axis scanner with the scanning step of $0.1 \mathrm{~mm}$ and the total scanned distance was $x=270 \mathrm{~mm}$. At each position, the signals were recorded to form a B-scan image of the ultrasonic guided waves propagating in the lap welded stainless steel plates. In order to improve the signal to noise ratio, the averaging of the eight signals at each measurement position was used also. The initial distance between transducers was set to be $\Delta x=40 \mathrm{~mm}$. It was selected so that asymmetric $A_{0}$ and symmetric $S_{0}$ guided wave modes would be separate in time domain already at the initial measurement position. Oil was used as the coupling material between transducers and test sample. Then the transmitter was attached to the second position along the edge and the scanning along the $x$ axis was repeated. The distance between each measurement position along the plate edge was $50 \mathrm{~mm}$, in total the measurements were performed across $450 \mathrm{~mm}$ of the edge. This enabled investigation of the test sample in the area where the width of the lap joint overlap zone $\Delta l$ is gradually changing from $4 \mathrm{~mm}$ up to $13 \mathrm{~mm}$ with steps of $1 \mathrm{~mm}$.

The measured signals in the form of a B-scan image (in the case of $4 \mathrm{~mm}$ overlap width) are presented in Figure 11a. Dashed lines denote the positions of the lap welds. In the B-scan image, the pattern of the propagating symmetric $\mathrm{S}_{0}$ and asymmetric $\mathrm{A}_{0}$ UGW modes could be clearly observed, as well the occurring reflection and mode conversion on the weld. The wavenumber-frequency analysis has been reported as an effective means for wave mode identification and propagation analysis. The wavenumber-frequency representation of time-space wavefield data $u(x, t)$ was performed by using the 2D Fourier transform (FT), which is defined as [50-56]:

$$
U(k, f)=\int_{-\infty}^{+\infty} \int_{-\infty}^{+\infty} u(x, t) e^{-i(k x+\omega t)} \mathrm{d} x \mathrm{~d} t
$$

where, $x$ is the spatial coordinate, $t$ is the time, $\omega$ is the angular frequency, $k$ is the wavenumber. Taking into account that $k=\omega / c_{\mathrm{ph}}$, the $U(k, f)$ can be easily transformed into $U\left(c_{\mathrm{ph} f} f\right)$. The reconstructed patterns of the dispersion curves of the ultrasonic guided wave modes propagating in the welded plate are presented in Figure 11b.

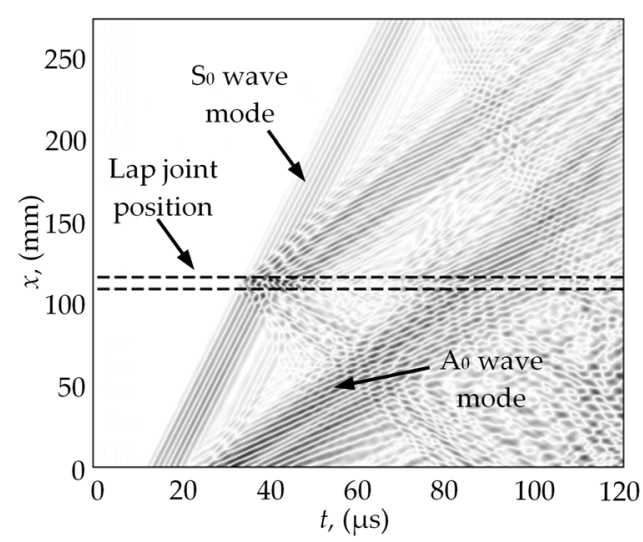

(a)

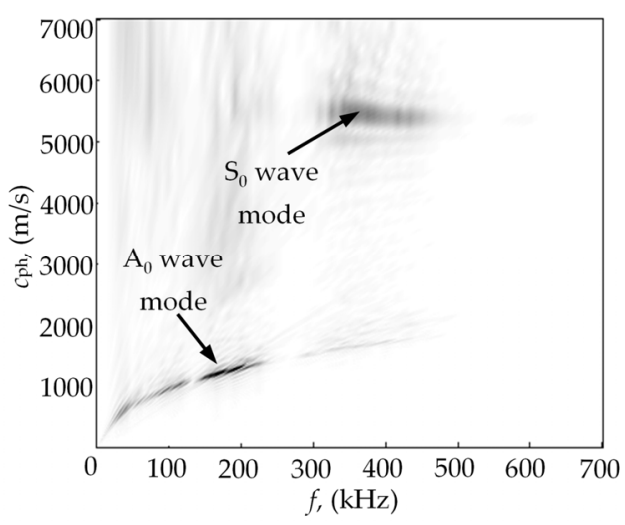

(b)

Figure 11. (a) An experimentally obtained B-scan image of the ultrasonic guided waves propagating through the lap joint welded plates in the case of the $4 \mathrm{~mm}$ overlap zone width; (b) reconstructed guided waves dispersion curve pattern by using 2D Fourier transform (FT).

From the results presented in Figure 11, it was observed that the most dominant and strongest propagating ultrasonic guided wave mode in the investigated test sample is the asymmetric $A_{0}$ wave 
mode. It could be explained by the fact that, for reception, the thickness mode ultrasonic transducer was used. Such a transducer has an essentially higher sensitivity to the out-of-plane $u_{y}$ displacement component which is dominant for asymmetric $\mathrm{A}_{0}$ wave mode motion. This is mainly due to the attached protector, which possesses a special shape, enabling it to record the modes with a dominant longitudinal component. Nevertheless, the propagating symmetric $S_{0}$ wave mode, which has lower amplitude, can also be clearly observed. It can also be noticed, that the asymmetric $\mathrm{A}_{0}$ guided wave mode in the investigated test sample was generated at the lower $40-450 \mathrm{kHz}$ frequency range. Meanwhile, the symmetric $S_{0}$ wave mode was generated at the $320-450 \mathrm{kHz}$ frequency range.

In order to separate the signals of symmetric $S_{0}$ wave mode propagating in forward direction from the reflected waves and from other guided wave modes, the 2D filtering in the wavenumber-frequency domain was used. The filtering process can be mathematically expressed as the product between the wavenumber-frequency spectrum $U(k, f)$ and filter function $W(k, f)[52,53,55]$ :

$$
U_{\mathrm{W}}(k, f)=U(k, f) \cdot W(k, f)
$$

where, $W(k, f)$ is the $2 \mathrm{D}$ bandpass filter in the wavenumber-frequency domain and $U_{\mathrm{W}}(k, f)$ is the filtered $2 \mathrm{D}$ spectrum. The filtered spectrum $U_{\mathrm{W}}(k, f)$ is then transformed back into the space-time domain using the inverse 2D FFT in order to obtain the filtered wavefield $u_{\mathrm{W}}(x, t)$ [55]

$$
u_{\mathrm{W}}(x, t)=\mathrm{FT}_{2 \mathrm{D}}^{-1}\left[U_{\mathrm{W}}(k, f)\right]
$$

The filtered $2 \mathrm{D} U_{\mathrm{W}}(k, f)$ spectrum converted into the phase velocity-frequency domain $U_{\mathrm{W}}\left(c_{\mathrm{ph}} f\right)$ and reconstructed afterwards B-scan $u_{\mathrm{W}}(x, t)$ are presented in Figure 12. As an example, the time waveforms of the experimentally measured UGW signals and experimental signals after using spatial mode filtering are presented in Figure 13.

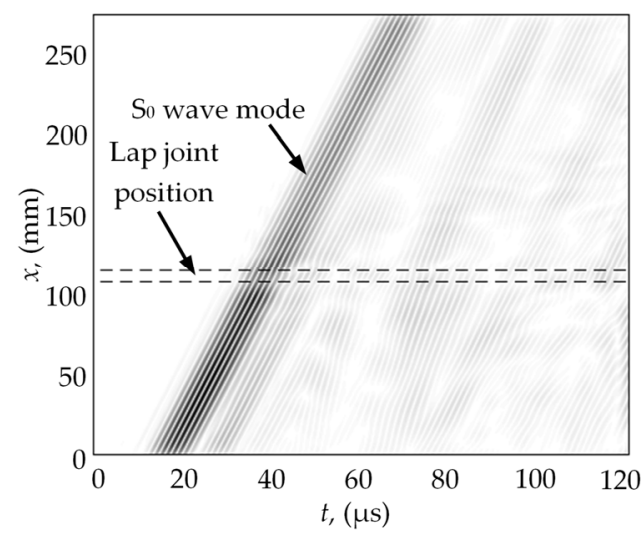

(a)

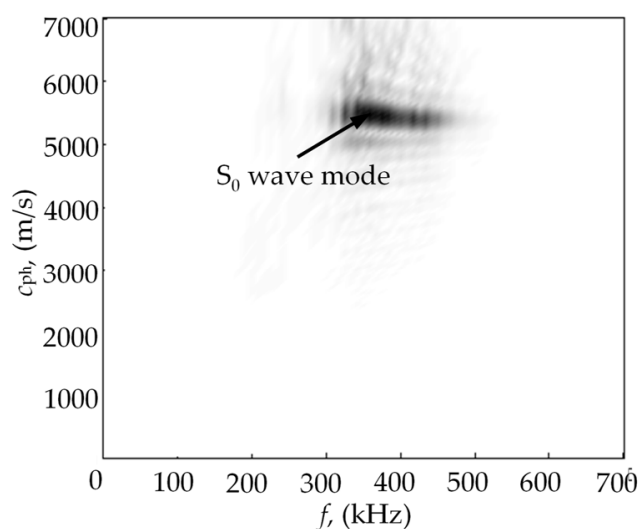

(b)

Figure 12. (a) Filtered B-scan image of the ultrasonic guided waves propagating through the lap joint welded plates in the case of the $4 \mathrm{~mm}$ overlap zone width; (b) reconstructed guided waves dispersion curve pattern by using 2D FT from filtered data.

As can be seen from the presented B-scan, the other guided wave modes and reflected waves are completely filtered. Two signals were selected for the assessment of transmission losses on the lap weld, one before the weld and another one after guided waves are transmitted through weld. The first one, used as the reference signal, was measured at the distance $90 \mathrm{~mm}$ from the transmitter or edge of the plate. Another one was measured at $265 \mathrm{~mm}$ distance away from the transmitter. The Hanning time window was used to select the segment of the signal correponding to the first burst of the propagating $S_{0}$ wave mode. The transmission losses $\alpha_{S 0}(f)$ on the lap weld of the symmetric $S_{0}$ guided wave mode in the case of different width $\Delta l$ lap joint connections were estimated according to Equation (3) 
presented earlier by comparing the frequency spectra of the $S_{0}$ guided wave mode measured before and after it is transmitted through the lap joint weld. The transmission losses $\alpha_{S_{0}}(f)$ for the particular overlap zone width $\Delta l$ were estimated by taking the value corresponding to the frequency $f=400 \mathrm{kHz}$. The obtained dependency of the transmission losses $\alpha_{S 0}(f=400, \Delta l)$ versus overlap zone width are presented in Figure 14. For comparison, the dependency obtained by FE modelling is also presented.

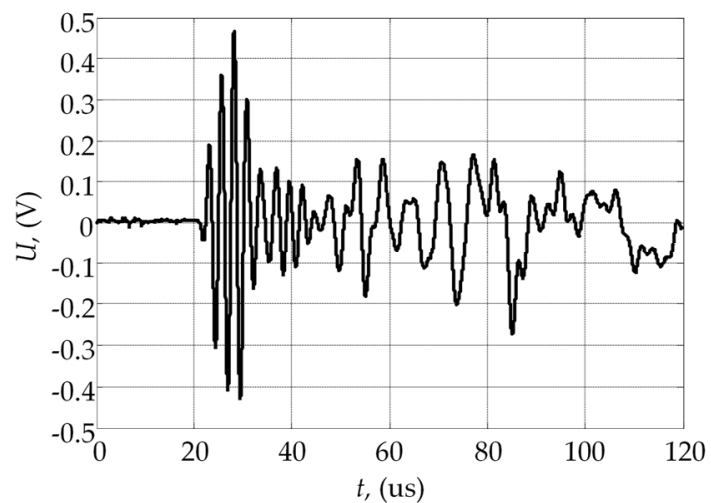

(a)

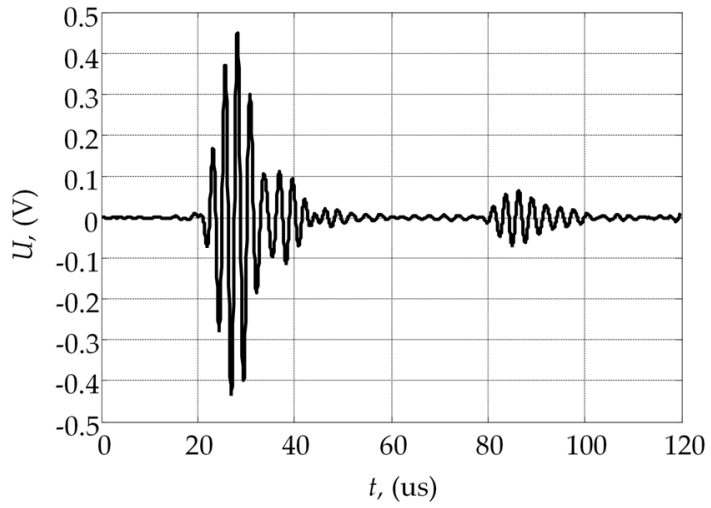

(c)

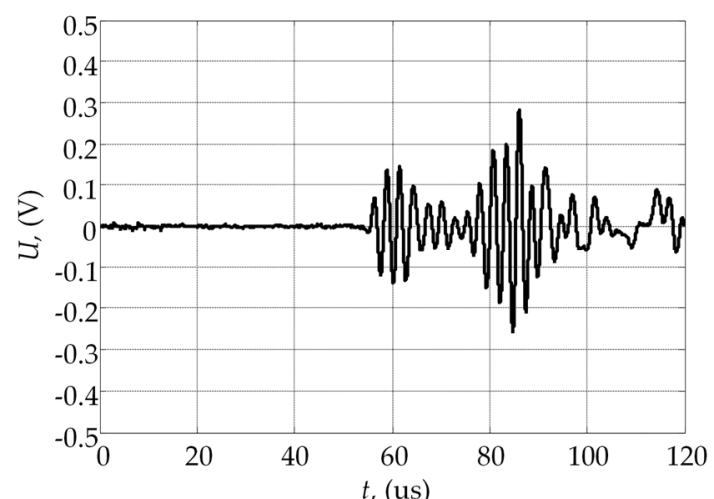

(b)

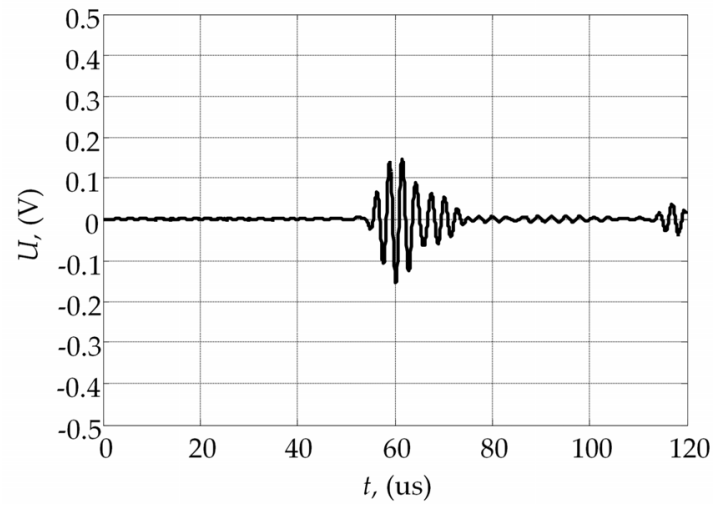

(d)

Figure 13. Waveforms of the ultrasonic guided wave signals measured: (a) before lap joint weld; (b) after lap joint weld; (c) waveform of the signal before the lap joint weld after applying spatial mode filtering; (d) waveform of the signal after the lap joint weld after applying spatial mode filtering.

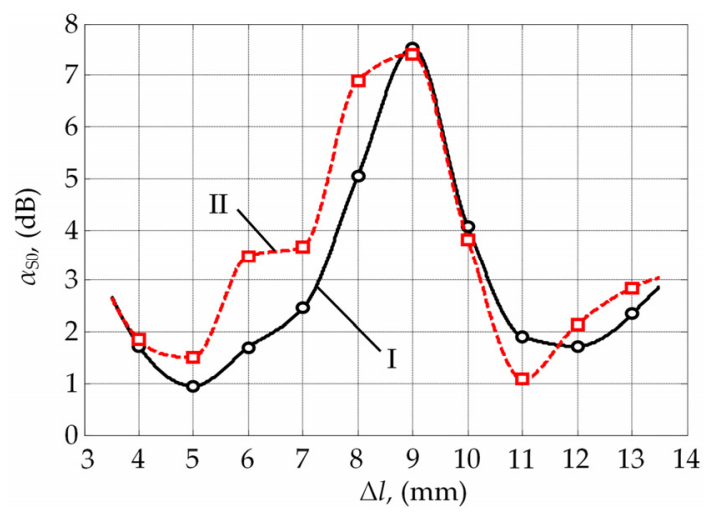

Figure 14. The transmission losses $\alpha_{S_{0}}(f)$ of the $S_{0}$ mode obtained by I: using numerical simulation finite element (FE) method, II: experimental measuring.

It can be observed that experimentally measured transmission losses $\alpha_{S_{0}}(f)$ of the symmetric $\mathrm{S}_{0}$ guided wave mode possess a variation similar to those obtained by finite element modelling. It was 
estimated that the highest transmission losses are obtained in the case of the $9 \mathrm{~mm}$ overlap zone width and are approximately $7.6 \mathrm{~dB}$. This maximum loss occurs due to interference of the waves directly propagated through the lap joint weld and the waves reflected by the free edge of the lap joint. Meanwhile, the observed differences from the numerical results are mainly conditioned by mounting of the transmitting transducer to the edge of the plate, i.e., parallelism of fixing that directly affects the acoustical contact and, in the case of amplitude measurements, is are particularly important.

\section{Conclusions}

The ultrasonic guided wave propagation through the lap joint welded plates used for the construction of the fuel tank floor were investigated by estimating the influence of the lap joint overlap width, operation frequency, and additional plate bonding on the transmission losses. The performed numerical investigation and experiment demonstrated that the transmission losses of the $\mathrm{S}_{0}$ wave mode can vary in the range of $2 \mathrm{~dB}$ to $8 \mathrm{~dB}$ depending on the ratio between lap joint width and wavelength. In addition, it was demonstrated that the additional bonding in the overlap zone caused by such factors as moisture retention, pressure, and corrosion can essentially reduce the overall transmission losses of the through lap welds transmitted guided waves.

Author Contributions: Audrius Jankauskas designed and performed numerical modelling, performed the experiments, analyzed the data, and wrote the manuscript; Liudas Mazeika as supervisor helped to perform analysis and interpretation of results with constructive discussions, corrected the draft of the paper, and contributed to the writing of the final revision of the paper.

Conflicts of Interest: The authors declare no conflict of interest.

\section{References}

1. Kasai, N.; Sekine, K.; Maruyama, H. Non-destructive evaluation method for far-side corrosion type flaws in oil storage tank bottom floors using the magnetic flux leakage technique. J. Jpn. Pet. Inst. 2008, 46, 126-132. [CrossRef]

2. Kasai, N.; Fujiwara, Y.; Sekine, K.; Sakamoto, T. Evaluation of back-side flaws of the bottom plates of an oil-storage tank by the RFECT. NDT E Int. 2008, 41, 525-529. [CrossRef]

3. Bagavathiappan, S.; Lahiri, B.B.; Saravanan, T.; Philip, J.; Jayakumar, T. Infrared thermography for condition monitoring-A review. Infrared Phys. Technol. 2013, 60, 35-55. [CrossRef]

4. Marinetti, S.; Vavilov, V. IR thermographic detection and characterization of hidden corrosion in metals: General analysis. Corros. Sci. 2010, 52, 865-872. [CrossRef]

5. Edalati, K.; Rastkhah, N.; Kermani, A.; Seiedi, M.; Movafeghi, A. The use of radiography for thickness measurement and corrosion monitoring in pipes. Int. J. Press. Vessels Pip. 2006, 83, 736-741. [CrossRef]

6. Nowak, M.; Baran, I.; Schmidt, J.; Ono, K. Acoustic emission method for solving problems in double bottom storage tanks. J. Acoust. Emiss. 2009, 27, 272-280.

7. Rose, J.L. Ultrasonic guided waves in structural health monitoring. Key Eng. Mater. 2004, 270-273, $14-21$. [CrossRef]

8. Zhao, X.; Royer, R.L.; Owens, S.E.; Rose, J.L. Ultrasonic Lamb wave tomography in structural health monitoring. Smart Mater. Struct. 2011, 20, 105002. [CrossRef]

9. Lowe, M.J.S.; Alleyne, D.N.; Cawley, P. Defect detection in pipes using guided waves. Ultrasonics 1998, 36, 147-154. [CrossRef]

10. Alleyne, D.N.; Pavlakovic, B.; Lowe, M.J.S.; Cawley, P. Rapid, long range inspection of chemical plant pipework using guided waves. AIP Conf. Proc. 2001, 557, 180-187.

11. Demma, A.; Cawley, P.; Lowe, M.; Roosenbrand, A.G.; Pavlakovic, B. The reflection of guided waves from notches in pipes: A guide for interpreting corrosion measurements. NDT E Int. 2004, 37, 167-180. [CrossRef]

12. Leinov, E.; Lowe, M.J.S.; Cawley, P. Investigation of guided wave propagation and attenuation in pipe buried in sand. J. Sound Vib. 2015, 347, 96-114. [CrossRef]

13. Rose, J.L.; Avioli, M.J.; Mudge, P.; Sanderson, R. Guided wave inspection potential of defects in rail. NDT E Int. 2004, 37, 153-161. [CrossRef] 
14. Moustakidis, S.; Kappatos, V.; Karlsson, P.; Selcuk, C.; Gan, T.; Hrissagis, K. An intelligent methodology for railways monitoring using ultrasonic guided waves. J. Nondestruct. Eval. 2014, 33, 694-710. [CrossRef]

15. Legg, M.; Yücel, M.K.; Kappatos, V.; Selcuk, C.; Gan, T. Increased range of ultrasonic guided wave testing of overhead transmission line cables using dispersion compensation. Ultrasonics 2015, 62, 35-45. [CrossRef] [PubMed]

16. Diligent, O.; Grahn, T.; Boström, A.; Cawley, P.; Lowe, M.J.S. The low-frequency reflection and scattering of the $\mathrm{S}_{0}$ Lamb mode from a circular through-thickness hole in a plate: Finite Element, analytical and experimental studies. J. Acoust. Soc. Am. 2002, 112, 2589-2601. [CrossRef] [PubMed]

17. Demma, A.; Cawley, P.; Lowe, M. Scattering of the fundamental shear horizontal mode from steps and notches in plates. J. Acoust. Soc. Am. 2003, 113, 1880-1891. [CrossRef] [PubMed]

18. Diligent, O.; Lowe, M.J.S. Reflection of the $\mathrm{S}_{0}$ Lamb mode from a flat bottom circular hole. J. Acoust. Soc. Am. 2005, 118, 2869-2879. [CrossRef]

19. Ma, J.; Cawley, P. Low-frequency pulse echo reflection of the fundamental shear horizontal mode from part-thickness elliptical defects in plates. J. Acoust. Soc. Am. 2010, 127, 3485-3493. [CrossRef] [PubMed]

20. Carandente, R.; Ma, J.; Cawley, P. The scattering of the fundamental torsional mode from axi-symmetric defects with varying depth profile in pipes. J. Acoust. Soc. Am. 2010, 127, 3440-3448. [CrossRef] [PubMed]

21. Løvstad, A.; Cawley, P. The reflection of the fundamental torsional guided wave from multiple circular holes in pipes. NDT E Int. 2011, 44, 553-562. [CrossRef]

22. Løvstad, A.; Cawley, P. The reflection of the fundamental torsional mode from pit clusters in pipes. NDT E Int. 2012, 46, 83-93. [CrossRef]

23. Cobb, A.C.; Kwun, H.; Caseres, L.; Janega, G. Torsional guided wave attenuation in piping from coating, temperature, and large-area corrosion. NDT E Int. 2012, 47, 163-170. [CrossRef]

24. Carandente, R.; Lovstad, A.; Cawley, P. The influence of sharp edges in corrosion profiles on the reflection of guided waves. NDT E Int. 2012, 52, 57-68. [CrossRef]

25. Kwun, H.; Kim, S.Y.; Choi, M.S.; Walker, S.M. Torsional guided-wave attenuation in coal-tar-enamel-coated, buried piping. NDT E Int. 2004, 37, 663-665. [CrossRef]

26. Chen, F.; Wilcox, P.D. The effect of load on guided wave propagation. Ultrasonics 2007, 47, 111-122. [CrossRef] [PubMed]

27. Lanza di Scalea, F.; Rizzo, P.; Marzani, A. Propagation of ultrasonic guided waves in lap-shear adhesive joints: Case of incident $\mathrm{A}_{0}$ Lamb wave. J. Acoust. Soc. Am. 2004, 115, 146-156. [CrossRef] [PubMed]

28. Santos, M.J.; Faia, P. Propagation of ultrasonic lamb waves in aluminium adhesively bonded lap joints and in single plates. Res. Nondestruct. Eval. 2009, 20, 178-191. [CrossRef]

29. Castaings, M. SH ultrasonic guided waves for the evaluation of interfacial adhesion. Ultrasonics 2014, 54, 1760-1775. [CrossRef] [PubMed]

30. Dalton, R.P.; Cawley, P.; Lowe, M.J.S. The potential of guided waves for monitoring large areas of metallic aircraft fuselage structure. J. Nondestruct. Eval. 2001, 20, 29-46. [CrossRef]

31. Choi, M.S.; Kim, S.J. Reflection and transmission of normal incidence SH0 waves at a lap joint of two plates of the same material and thickness. J. Korean Phys. Soc. 2006, 49, 1955-1960.

32. Siryabe, E.; Renier, M.; Meziane, A.; Castaings, M. The transmission of lamb waves across adhesively bonded lap joints to evaluate interfacial adhesive properties. Phys. Procedia 2015, 70, 541-544. [CrossRef]

33. Rhee, I.; Choi, E.; Roh, Y. Guided wave propagation induced by piezoelectric actuator in bolted thin steel members. KSCE J. Civ. Eng. 2012, 16, 398-406. [CrossRef]

34. Comot, P.; Bocher, P.; Belanger, P. Ultrasonic guided wave inspection of Inconel 625 brazed lap joints. Proc. SPIE 2016, 9804, 980408.

35. Hayashi, T.; Song, W.; Rose, J.L. Guided wave dispersion curves for a bar with an arbitrary cross-section, a rod and rail example. Ultrasonics 2003, 41, 175-183. [CrossRef]

36. Hayashi, T.; Kawashima, K.; Rose, J.L. Calculation for guided waves in pipes and rails. Key Eng. Mater. 2004, 270-273, 410-415. [CrossRef]

37. Mažeika, L.; Kažys, R.; Raišutis, R.; Šliteris, R. Ultrasonic guided wave tomography for the inspection of the fuel tanks floor. Int. J. Mater. Prod. Technol. 2011, 41, 128-139. [CrossRef]

38. Moser, F.; Jacobs, L.; Qu, J. Application of Finite Element Methods to Study Transient Wave Propagation in Elastic Wave Guides; Thompson, D., Chimenti, D., Eds.; Springer: New York, NY, USA, 1998; pp. 161-167. 
39. Moser, F.; Jacobs, L.J.; Qu, J. Modeling elastic wave propagation in waveguides with the finite element method. NDT E Int. 1999, 32, 225-234. [CrossRef]

40. Cerniglia, D.; Pantano, A.; Montinaro, N. 3D simulations and experiments of guided wave propagation in adhesively bonded multi-layered structures. NDT E Int. 2010, 43, 527-535. [CrossRef]

41. Sorohan, Ş.; Constantin, N.; Găvan, M.; Anghel, V. Extraction of dispersion curves for waves propagating in free complex waveguides by standard finite element codes. Ultrasonics 2011, 51, 503-515. [CrossRef] [PubMed]

42. Noh, G.; Bathe, K. An explicit time integration scheme for the analysis of wave propagations. Comput. Struct. 2013, 129, 178-193. [CrossRef]

43. Asmus, A.; Lammering, R. Actual time integration methods for elastic wave propagation analysis. PAMM 2014, 14, 857-858. [CrossRef]

44. Mirbagheri, Y.; Nahvi, H.; Parvizian, J.; Düster, A. Reducing spurious oscillations in discontinuous wave propagation simulation using high-order finite elements. Comput. Math. Appl. 2015, 70, 1640-1658. [CrossRef]

45. Mal, A.; Lih, S.; Guo, D. Ultrasonic Characterization of Defects in Lap Joints; Thompson, D., Chimenti, D., Eds.; Springer: New York, NY, USA, 1995; pp. 2059-2064.

46. Chang, Z.; Guo, D.; Mal, A. Lamb Wave Propagation across a Lap Joint; Thompson, D., Chimenti, D., Eds.; Springer: New York, NY, USA, 1996; pp. 185-192.

47. Vladišauskas, A.; Šliteris, R.; Raišutis, R.; Seniūnas, G. Contact ultrasonic transducers for mechanical scanning systems. Ultragarsas (Ultrasound) 2010, 65, 30-35.

48. Vladišauskas, A.; Raišutis, R.; Šliteris, R.; Seniūnas, G.; Jankauskas, A. Investigation of the characteristics of the low frequency broadband contact transducers. Ultragarsas (Ultrasound) 2010, 65, 41-44.

49. Vladišauskas, A.; Mažeika, L.; Šliteris, R.; Raišutis, R.; Jankauskas, A. Pulse and frequency responses of broadband low frequency ultrasonic transducers. Ultragarsas (Ultrasound) 2011, 66, 32-39. [CrossRef]

50. Alleyne, D.N.; Cawley, P. A 2-dimensional Fourier transform method for the quantitative measurement of Lamb modes. In Proceedings of the 17th Annual Review, La Jolla, CA, USA, 15-20 July 1990; Volume 2, pp. 1143-1146.

51. Duflo, H.; Morvan, B.; Izbicki, J.-L. Interaction of lamb waves on bonded composite plates with defects. Compos. Struct. 2007, 79, 229-233. [CrossRef]

52. Ruzzene, M. Frequency-wavenumber domain filtering for improved damage visualization. Smart Mater. Struct. 2007, 16, 2116. [CrossRef]

53. Michaels, T.E.; Michaels, J.E.; Ruzzene, M. Frequency-wavenumber domain analysis of guided wavefields. Ultrasonics 2011, 51, 452-466. [CrossRef] [PubMed]

54. Yu, L.; Tian, Z. Lamb wave structural health monitoring using a hybrid PZT-laser vibrometer approach. Struct. Health Monit. 2013, 12, 469-483. [CrossRef]

55. Tian, Z.; Yu, L. Lamb wave frequency-wavenumber analysis and decomposition. J. Intell. Mater. Syst. Struct. 2014, 25, 1107-1123. [CrossRef]

56. Yu, L.; Tian, Z. Case study of guided wave propagation in a one-side water-immersed steel plate. Case Stud. Nondestruct. Test. Eval. 2015, 3, 1-8. [CrossRef]

(C) 2016 by the authors; licensee MDPI, Basel, Switzerland. This article is an open access article distributed under the terms and conditions of the Creative Commons Attribution (CC-BY) license (http://creativecommons.org/licenses/by/4.0/). 